\title{
Adaptability Analysis of Four-Leg Hydraulic Support with Large Mining Height under Impact Dynamic Load
}

\author{
Dalong Wang, ${ }^{1,2}$ Xiaoteng Zeng $\mathbb{D}^{1},{ }^{1}$ Guofa Wang, ${ }^{3,4}$ and Ran Li $\mathbb{C}^{2}$ \\ ${ }^{1}$ School of Mechanical Electronic and Information Engineering, China University of Mining and Technology - Beijing, \\ Beijing 100083, China \\ ${ }^{2}$ Beijing Tianma Intelligent Control Technology Co., Ltd., Beijing 101399, China \\ ${ }^{3}$ China Coal Technology and Engineering Group Corp, Beijing 100013, China \\ ${ }^{4}$ Coal Mining Research Institute, China Coal Technology and Engineering Group, Beijing 100013, China
}

Correspondence should be addressed to Xiaoteng Zeng; zengxt@cumtb.edu.cn

Received 7 October 2021; Accepted 8 December 2021; Published 27 February 2022

Academic Editor: Xuesheng Liu

Copyright ( 2022 Dalong Wang et al. This is an open access article distributed under the Creative Commons Attribution License, which permits unrestricted use, distribution, and reproduction in any medium, provided the original work is properly cited.

In order to comprehensively analyze the adaptability of four-leg hydraulic support with large mining height under impact dynamic load, this paper adopts HyperMesh software to conduct a flexible pretreatment for the top beam, shield beam, and front and rear rods. The numerical simulation model of four-leg hydraulic support is established with ADAMS, where variable stiffness spring is used to replace columns to simulate their elastic characteristics. Building on analysis of the specific parameters of the support, this paper attempts to study the adaptability of the hydraulic support with impact dynamic load acting on the top beam. Additionally, the impact coefficient $I$ and the excitation coefficient $E$ have been introduced to transform the analysis results and optimize the evaluation method of the response degree of the top beam under impact load. Consequently, the response characteristics of the columns and pins at the hinged joints under various coupling states of the surrounding rock are found. Meanwhile, the paper has made a detailed comparison on the stress state of hydraulic support with different impact loads acting on the top beam. The adaptability change rule of the impact dynamic load under various impact conditions has been explored, which is of great significance to the optimization and strength design of four-leg hydraulic support with large mining height.

\section{Introduction}

In recent years, as the one-time fully mechanized mining technology with large mining height gains momentum, the hydraulic support is also developing towards larger mining height. In the scheme of one-time full height mining with large mining height, the hydraulic support equipment is gradually developing to a larger size due to the large mining height [1-3]. According to the actual use of the hydraulic support with large mining height, it turns out to be a necessity for making a targeted analysis on the adaptability of its support and face guard. International scholars have made more attempts on this problem. Prusek and Brady [4-7] have, respectively, analyzed the roof response characteristics under various support and rock coupling conditions. The GRC theory is adopted to analyze and calculate the roof displacement variation law. Additionally, combined with field observation, the interaction between roof and support under the condition of natural roof caving in goaf has been analyzed, and the bearing characteristics of the hydraulic support have been obtained through continuous measurement along with the mining face. Polish scholar Szurgacz et al. [8] have tested the response characteristics of hydraulic support under static load and impact load of roof through experiments and pointed out the dangerous areas of stress concentration of support, which provides the theoretical guidance for measuring and evaluating the safety of hydraulic support under specific geological conditions. Witek et al. [9] from Poland Central Mining Research Institute have studied the stress distribution of hydraulic support under different working conditions by means of finite element analysis and laboratory test. The result suggests that the 
coupling form of wall rock has an impact on the stress distribution of support, and better coupling conditions can achieve the decrease in the stress concentration of support. Wang et al. [10] from CCRI (China Coal Research Institute) have fulfilled the establishment of the support and wall rock coupling model by the 3D parameter optimal dynamic design method and studied the overall working process of the support. Then, by analyzing the dynamic instability characteristics of hydraulic support, Wang et al. [11] have built the adaptability model of hydraulic support under various coupling relationships with wall rock, obtaining the support adaptability under various conditions, which provides theoretical guidance for the optimal design of hydraulic support. Subsequently, Wang and Ren et al. [12-16] have conducted numerous in-depth studies on the coupling adaptability of supports and surrounding rock, comprehensively studied the coupling theory of supports and surrounding rock of various types in fully-mechanized working face, and proposed changing the initial support force of hydraulic supports and optimizing the structural form to improve the stability control of supports and surrounding rock. Thus, it is concluded that the study of surrounding rock and hydraulic support as a whole helps to produce coal mine safely and efficiently. He [17] from China University of Mining and Technology (Beijing), carrying out theoretical research and simulation research on the supporting capacity of two-column and four-column hydraulic supports, respectively, has pointed out that the bearing area of hydraulic supports cannot fully reflect the bearing characteristics of supports, so it is necessary to establish a spatial model to comprehensively study the law of bearing adaptability of two hydraulic supports with the 8707 working face of Jinhuagong Mine as the test site to ensure the accuracy of theoretical analysis. Having divided the bearing state of hydraulic support into single zone bearing and double zone bearing, Meng [18] has studied the two column hydraulic support under two bearing states based on ADAMS software and pointed out the ultimate bearing capacity and bearing adaptability of hydraulic support under different working conditions. The results show that adjusting the parameters of the column and Jack is conducive to improving the adaptability between the top beam and the top plate of the hydraulic support, as well as the bearing capacity of the support. Based on the dynamic load model with hydraulic support, Li [19] from CCRI has comprehensively analyzed the impact dynamic load bearing characteristics of hydraulic support. The results indicate that the response characteristics of hydraulic support under dynamic load are greater than that under static load, which provides a theoretical basis for subsequent verification.

\section{Numerical Model of Four-Leg Hydraulic Support}

In order to analyze the bearing adaptability of hydraulic support under asymmetric load, it is necessary to enhance the flexibility of the 3D model of hydraulic support. Firstly, the structural components that need flexible processing should be successively imported into HyperMesh software, which is used to mesh these components. Meanwhile, rigid connection areas should be established at each hinge point and then exported in the file form of ".mnf". Secondly, the $3 \mathrm{D}$ model of the hydraulic support should be imported into ADAMS software as a whole to generate the simulation model of rigid hydraulic support. Then, the top beam, shield beam, and front and rear connecting rod components after flexible processing are used to replace the rigid components to form the rigid-flexible coupling simulation model with the base as the rigid body [20,21]. Finally, the corresponding motion control is added between each component to lock the base and the ground. Revolving pairs are added between the top beam and the shield beam, between the shield beam and the front and rear connecting rods, and between the front and rear connecting rods and the base. The friction coefficient is set at 0.3 to enable it to rotate around the pin shaft connection.

The research model of this paper is four-leg hydraulic support, and front and rear support adopt double telescopic upright post. In the different stages of the active support and passive bearing of the roof supported by the hydraulic support, the primary and secondary cylinder will show different stiffness. When the front and rear columns bear external loads, because of the emulsion is compressed in cylinder, the column shows the characteristic of elasticity. The pressure in the cylinder also varies with the degree of pressure. Therefore, in order to better simulate the column, this paper will use variable stiffness springs to replace the column for simulation analysis.

Combined with the working characteristics of the fourleg hydraulic support, the equivalent spring with variable stiffness can be defined according to the equivalent stiffness calculation equation of the hydraulic cylinder, as is shown in

$$
k=\frac{A \eta}{L_{y}},
$$

where $k$ is the stiffness coefficient of the equivalent spring, $A$ is the effective pressure area in the hydraulic cylinder, $\eta$ is the bulk modulus of elasticity of hydraulic fluids, and $L_{y}$ is the length of effective liquid column in hydraulic cylinder (varying with the height of the support).

When the column is in the third period, it is equivalent to the series stiffness coefficient of the two-stage hydraulic cylinder, and the above equation needs to be supplemented, as is shown in

$$
k=\frac{k_{1} \times k_{2}}{k_{1}+k_{2}},
$$

where $k_{1}$ is the equivalent stiffness coefficient of primary cylinder, $k_{2}$ is the equivalent stiffness coefficient of secondary cylinder, and $k$ is the stiffness coefficient of two-stage hydraulic cylinder series equivalent spring.

The relevant design parameters of front and rear columns are shown in Table 1.

At the same time, in order to test the change of the hydraulic support under the roof load and explore the reliability of the simulation model, a simulated roof is established above the top beam (the simulated roof is a rigid 
TABLE 1: Relevant parameters of front and rear columns.

\begin{tabular}{lcccc}
\hline Parameter & $\begin{array}{c}\text { Diameter of the primary } \\
\text { cylinder }(\mathrm{mm})\end{array}$ & $\begin{array}{c}\text { Diameter of the secondary } \\
\text { cylinder }(\mathrm{mm})\end{array}$ & $\begin{array}{c}\text { Diameter of the primary } \\
\text { column }(\mathrm{mm})\end{array}$ & $\begin{array}{c}\text { Diameter of } \\
\text { the secondary } \\
\text { column }(\mathrm{mm})\end{array}$ \\
\hline Front column & 400 & 290 & 380 & 260 \\
Rear column & 320 & 230 & 290 & 210 \\
\hline
\end{tabular}

body without flexible processing). And a moving pair is set between the simulated roof and the ground. The direction of its movement is vertically downward and always keeps parallel with the base. Impact model is defined between the roof and the top beam, as is shown in

$$
F_{c}=K_{H} \delta_{c}^{e}+C_{c} V_{c},
$$

where $F_{c}$ is the contact force between roof and top beam, $K_{H}$ is the plane contact impact stiffness (contact stiffness of collider surface), $\delta_{c}$ is the normal penetration depth of contact member, $e$ is the stiffness to force contribution gain, $C_{c}$ is the damping coefficient of the contact member, and $V_{c}$ is the normal relative velocity of the contact member.

The frictional force of the collision adopts Coulomb friction model, as is shown in

$$
F_{c f}=F_{c} f_{c} .
$$

Based on the above contents, a numerical simulation model is established by ADAMS software, as is shown in Figure 1.

\section{Adaptability Analysis of Hydraulic Support with Impact Load Acting on Top Beam}

3.1. Definition of Load's Position and Size. Based on the numerical simulation model mentioned above, the working height of the hydraulic support is set as $7 \mathrm{~m}$ from the perspective of rigid-flexible coupling analysis. In order to simulate the impact load on the upper surface of the top beam, point load is adopted directly on the top beam after the simulated roof failure treatment. Firstly, the loading position of each impact load is defined. With a total of 30 impact load loading positions, the width direction of the top beam of the hydraulic support is defined at the interval of $350 \mathrm{~mm}$, and the length direction is defined at the interval of $914 \mathrm{~mm}$. Secondly, the coordinate system is established on the upper surface of the top beam, as is shown in Figure 2, where $X$ coordinate axis represents the width direction of the top beam, $\mathrm{Y}$ coordinate axis represents the length direction of the top beam, and the origin $\mathrm{O}$ of the coordinate system is at the center of the width direction of the top beam. Finally, the loading position of each load is numbered according to the coordinate system. Along the $X$-axis direction, each impact load position is defined as $(-2, \mathrm{Y})$ to $(2, \mathrm{Y})$, and along the $Y$-axis direction, each impact load position is defined as $(\mathrm{X}, 1)$ to $(\mathrm{X}, 5)$.

In order to simulate a certain roof force that the hydraulic support has already borne before the roof fracture

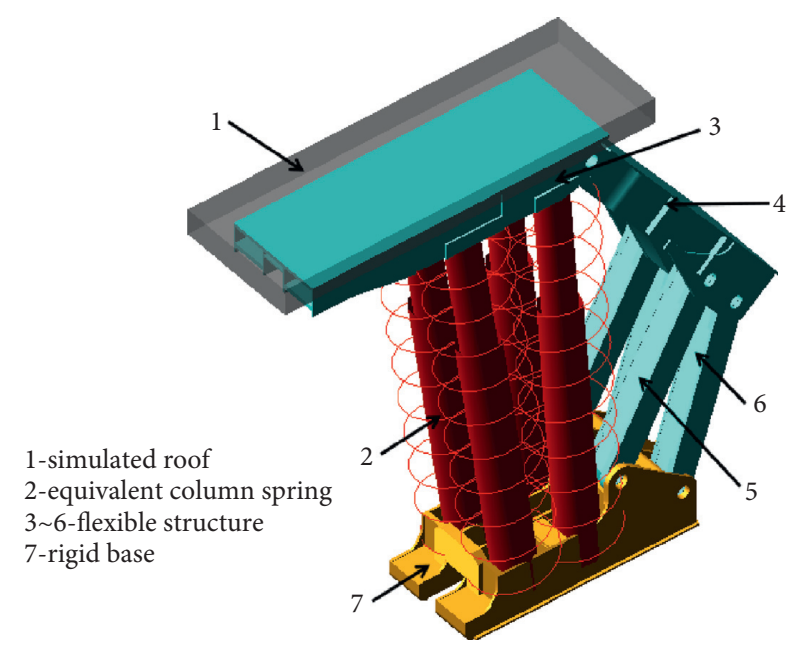

FIgURE 1: Numerical simulation model of hydraulic support.

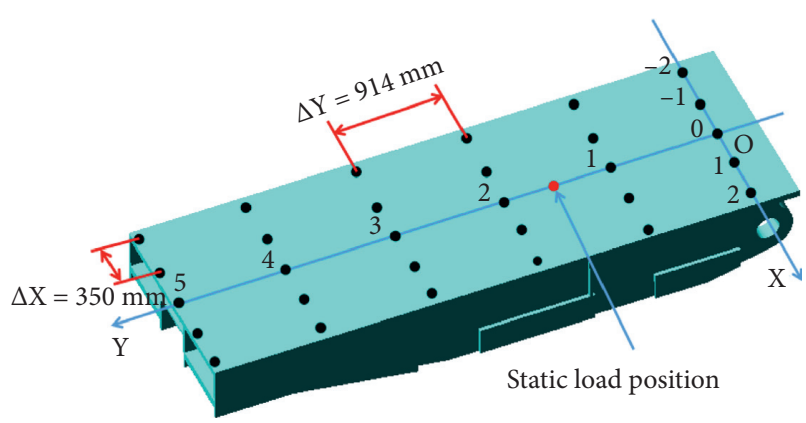

FIGURE 2: Loading position of top beam of hydraulic support.

posing the impact load on the support, the STEP function is firstly applied to the static load above the top beam until the end of the simulation experiment, and the applied position is at the maximum bearing load of the top beam with the load size being $6000 \mathrm{kN}$. After the stress of each hinge and column with hydraulic support tend to be stable (about $1.5 \mathrm{~s}$ ), the STEP function is applied to impose the impact load from $1.5 \mathrm{~s}$ with the impact duration being $0.05 \mathrm{~s}$ and the size being $1500 \mathrm{kN}$.

3.2. Support Adaptability Analysis of Top Beam Bearing Impact Load at Different Positions. Based on the above simulation settings, simulation experiments are carried out on the loading points at each position successively. After imposing the impact load, the steady-state response force and peak response force of front and rear columns are obtained, as is shown in Figures 3 and 4. 


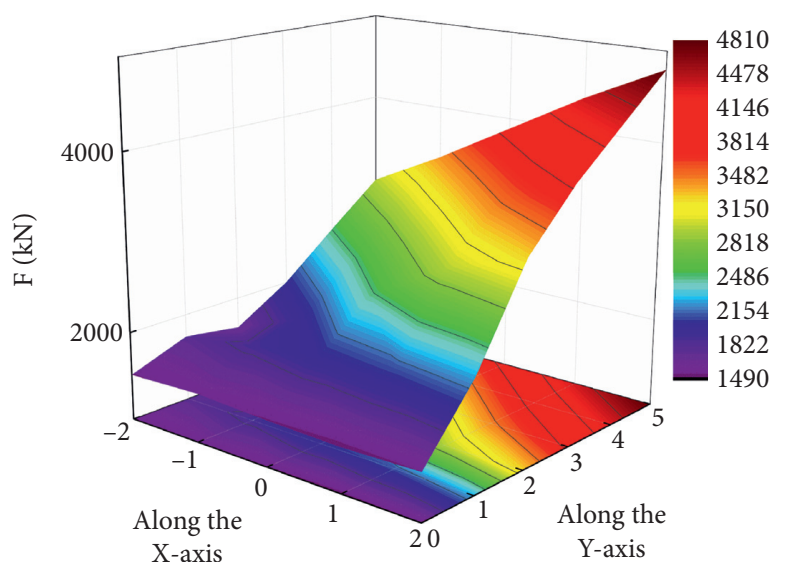

(a)

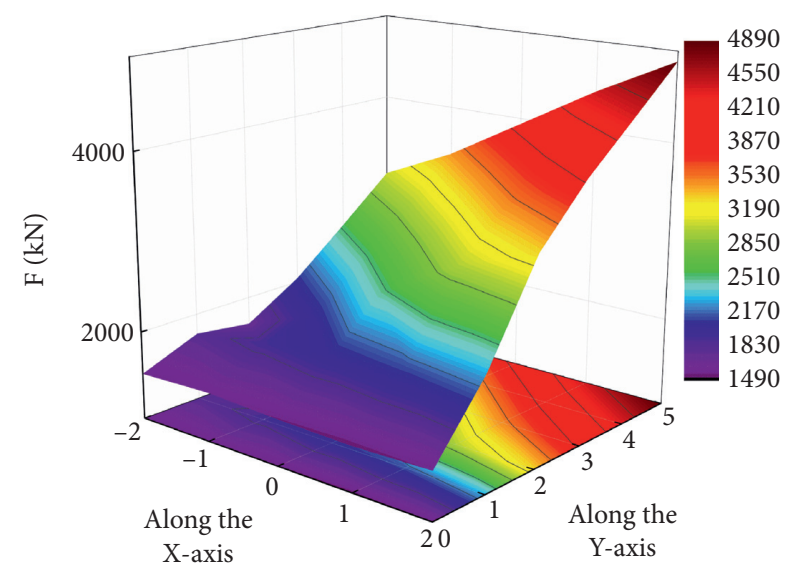

(b)

Figure 3: Response force of one side front column of hydraulic support. (a) Steady state response force of unilateral front column. (b) Peak response force of unilateral front column.

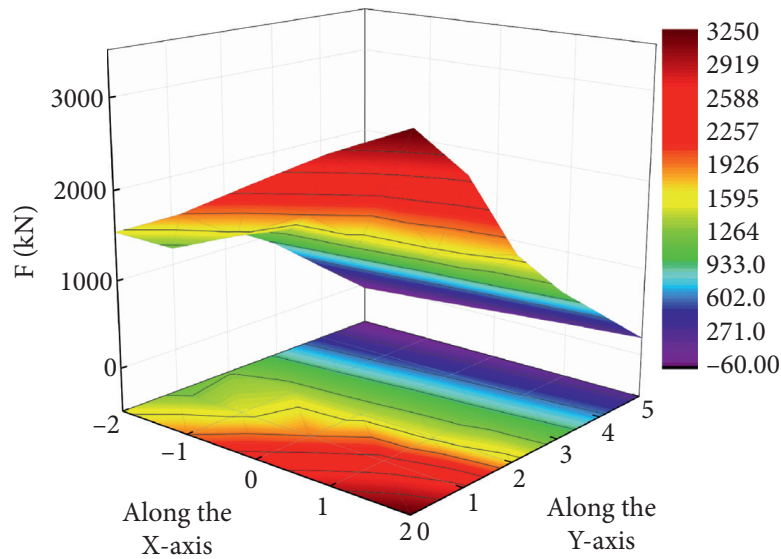

(a)

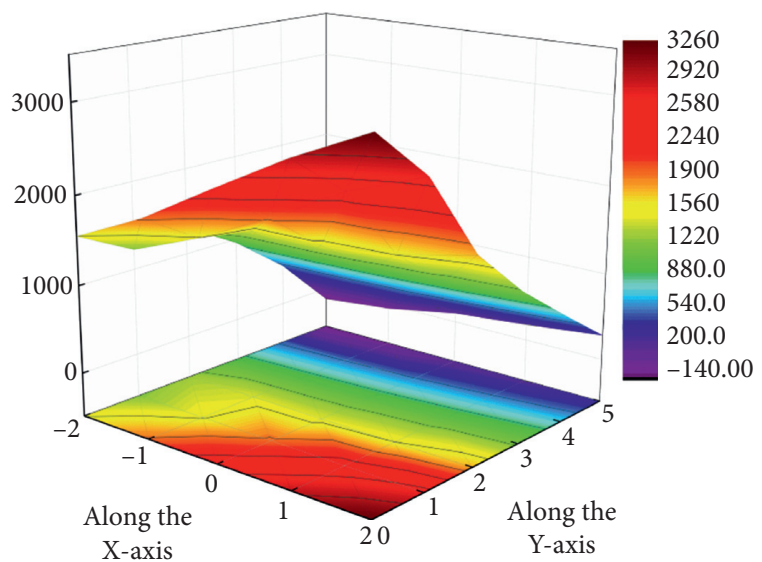

(b)

Figure 4: Response force of one side rear column of hydraulic support. (a) Steady state response force of unilateral rear column. (b) Peak response force of unilateral rear column.

According to the analysis on Figures 3 and 4, the steadystate response and the impact peak response of the front column tend to possess basically the same variation trend under the impact load. The impact load on the front end of the top beam is more intense than the impact pressure on the front column caused by the back end of the top beam. At the same time, the closer the impact load is to the front column of one side in the width direction of the top beam, the greater the pressure of the front column is under the impact load. The rear column of the hydraulic support is sensitive to the impact load of the front and back ends of the top beam. When the impact load is imposed at the back end of the top beam, the back column will bear greater pressure. When the impact load acts on the width direction of the top beam, the closer position to the column will cause the sharp increase in the load on the side rear column. Under the impact load of this position, the front and rear columns requiring hydraulic support should demand better impact adaptability.

The adaptability of the hinged pin shaft of the other structural parts of the hydraulic support to the impact load of the top beam is evaluated mainly by its response to the impact load. Therefore, in order to better evaluate the impact adaptability, the impact coefficient $I$ and the excitation coefficient $E$ are introduced to transform the analysis results. The transformation equation is shown in

$$
\begin{gathered}
I_{(X, Y)}=\frac{F_{\max }-F_{o}}{F_{I}}, \\
E_{(X, Y)}=\left|\frac{F_{\max }-F_{s}}{F_{s}}\right|,
\end{gathered}
$$


where $I_{(X, Y)}$ is the impact response coefficient of the pin at the hinge when the impact load is applied to the position $(\mathrm{X}, \mathrm{Y})$ of the top beam, $E_{(X, Y)}$ is the excitation response coefficient at the component hinge when the impact load is applied to the position $(\mathrm{X}, \mathrm{Y})$ of the top beam, $F_{\max }$ is the peak response force of the corresponding hinge point under external impact load, $F_{o}$ is the size of the steady-state response force at the hinge point under static load when the hydraulic support is only subjected to static load, $F_{s}$ is the steady-state response forces at the hinge points after the impact load is applied to the top beam, and $F_{I}$ is the size of the applied impact load.

When the external impact load acts on the top beam at different positions, the impact response and excitation response at the hinge point will get different feedback results. Based on this, the impact adaptability of the bracket hinge point under the impact position can be evaluated. The response characteristics of the hinge point between the top beam and the shield beam under impact load are shown in Figure 5.

According to the impact response coefficient, when the impact load acts on the front end of the top beam and is close to the side hinge point in the width direction, the stress increase at the hinge point is larger, and the pin shaft is prone to fracture and damage. When the impact load acts on the back end of the top beam, the stress variation amplitude is relatively small, requiring the low load requirement on the hinge pin bearing. Combined with the analysis of impact response coefficient and excitation response coefficient of the hinge point of the top beam-shield beam, it can be concluded that when the impact load acts on the front end of the top beam, the stress of the hinge point fluctuates greatly with high sensitivity degree, and the pin shaft is prone to damage and fail. Therefore, when the impact load acts on the back end of the top beam, the impact load adaptability of the hinge point is relatively good.

This paper analyzes the shield beam and front-rear connecting rod hinge point. When the top beam of the fourlink mechanism is subjected to impact load, the adaptability analysis results are shown in Figures 6 and 7. According to analysis, in the design optimization process of the hydraulic support, it should be noted that when the impact load acts on the front end of the top beam, the forces at the hinge points of the front and rear connecting rods both increase greatly. At this time, the hinge points of the front and rear connecting rods should be able to bear large loads to meet the requirements of use.

To be concluded, when the impact load acts on the front end of the top beam, the impact response forces at the hinge points of the front and rear connecting rods are obvious, and the response is more sensitive than that of the shock load acting on the back end of the top beam. Due to the high additional load borne by the four-link mechanism of the hydraulic support, the impact effect and excitation effect are not obvious when the impact load changes along the width of the top beam. Therefore, when the impact load moves along the width of the top beam, the four-link mechanism has a better ability to resist the partial load effect with a better impact load adaptability. According to the comparative analysis of front and rear connecting rods, it can be concluded that the impact adaptability of the rear connecting rod hinge point is more stable than that of the front connecting rod.

\section{Adaptability Analysis of Hydraulic Support with Impact Load Acting on Shield Beam}

4.1. Definition of Load's Position and Size. In order to comprehensively analyze the adaptability of the impact dynamic load at the hinge of the main component of the hydraulic support when the impact load acts on the shield beam under a variety of falling conditions, this section carries out simulation experiments by applying the impact load to the upper surface of the shield beam in the way of taking points at equal spacing. Thirty loading point positions are taken on the upper surface of the shield beam of the bracket. Meanwhile, a coordinate system is established on the upper surface with $\mathrm{O}$ as the origin $(\mathrm{O}$ point was the central position in the direction of the width of the shield beam). $X$-axis represents the direction of the width of the shield beam, and $Y$-axis represents the direction of its length. And each loading position is numbered, as is shown in Figure 8 . Along the width direction of the shield beam, each position is defined as $(-2, \mathrm{Y})$ to $(2, \mathrm{Y})$, and along the length of the shield beam, the positions of each impact load are defined as $(\mathrm{X}, 1)$ to $(\mathrm{X}, 5)$.

According to the above definition method, impact loads are applied to 30 positions successively in the same way as the loading method of the top beam. The STEP function is adopted to control the static load of $6000 \mathrm{kN}$, impact load of $1500 \mathrm{kN}$, load direction of vertical downward, and time of $0.05 \mathrm{~s}$, so as to obtain the adaptability of the bracket when the shield beam is imposed with impact load.

4.2. Adaptability Analysis of the Support with Impact Load Imposed on Shield Beam at Different Positions. When the shield beam is subjected to impact load, the stress analysis results of the front and rear columns are shown in Figures 9 and 10. According to the analysis of the variation rule of the steady-state response force of the front and rear columns in the two figures, it can be concluded that the impact load on the shield beam will decrease the pressure on the front column and increase the pressure on the back column in most cases, which means that when the impact load is large enough, it will further promote the unstable attitude of the head of the top beam of the hydraulic support, or even the overflow of the back column will occur, reducing the adaptability of the support to the roof load.

According to the analysis of the variation rule of the peak response force of the front and rear columns in the two figures, it can be concluded that the difference between the peak response force and the steady-state response force of the front column is larger than that in the front of the shield beam behind the upper surface of the shield beam, and the shock effect is more pronounced than other positions. It is shown that the adaptability of the hydraulic support is 


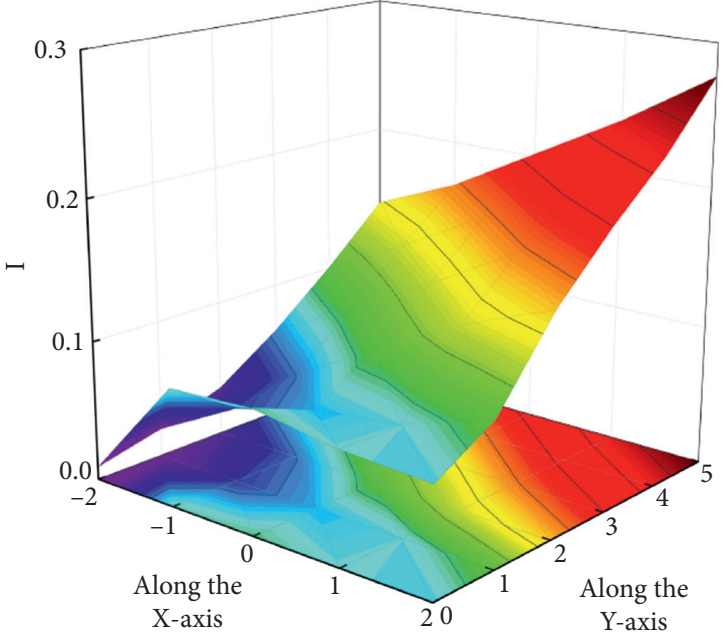

(a)

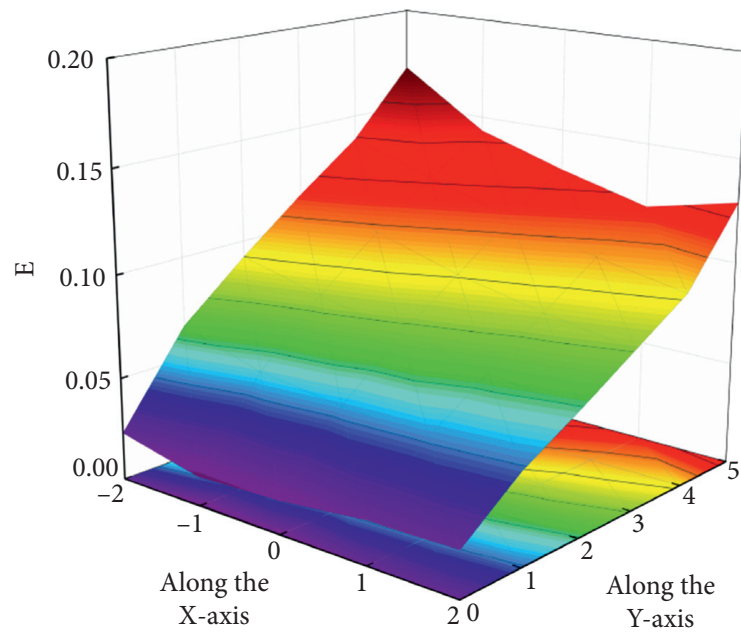

(b)

FIGURE 5: Response coefficient of hinge joint between top beam and shield beam. (a) Impact response coefficient between top beam and shield beam. (b) Excitation response coefficient between top beam and shield beam.

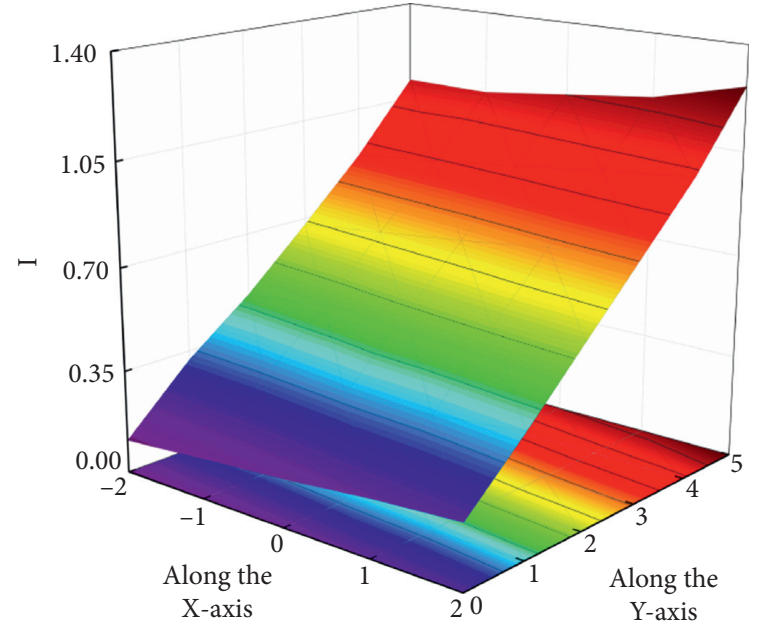

(a)

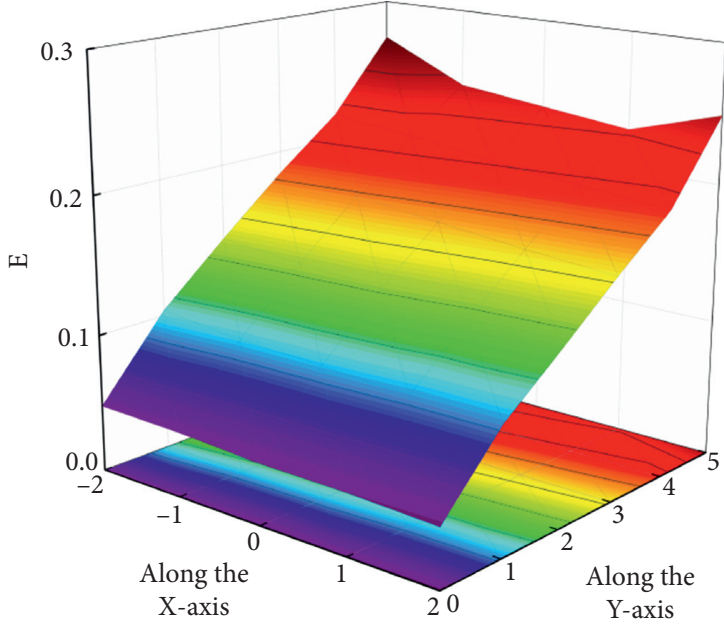

(b)

Figure 6: Response coefficient of hinge joint of front connecting rod. (a) Impact response coefficient of the front connecting rod. (b) Excitation response coefficient of the front connecting rod.

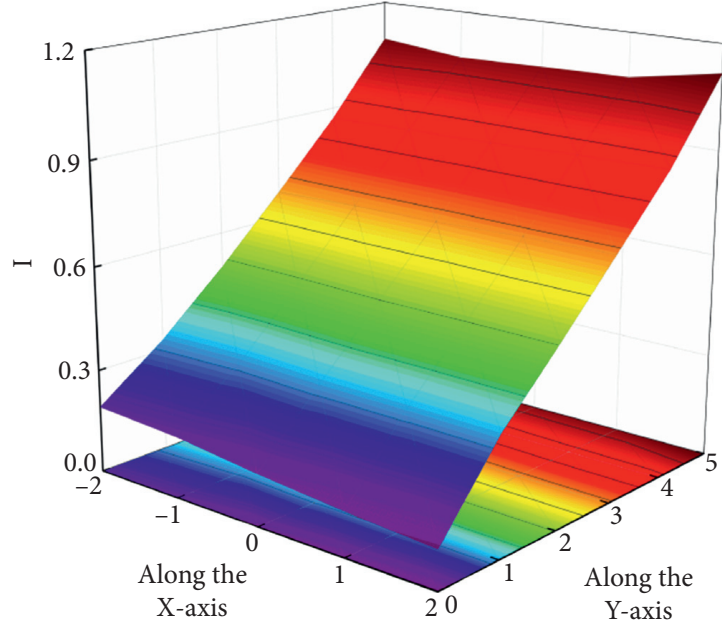

(a)

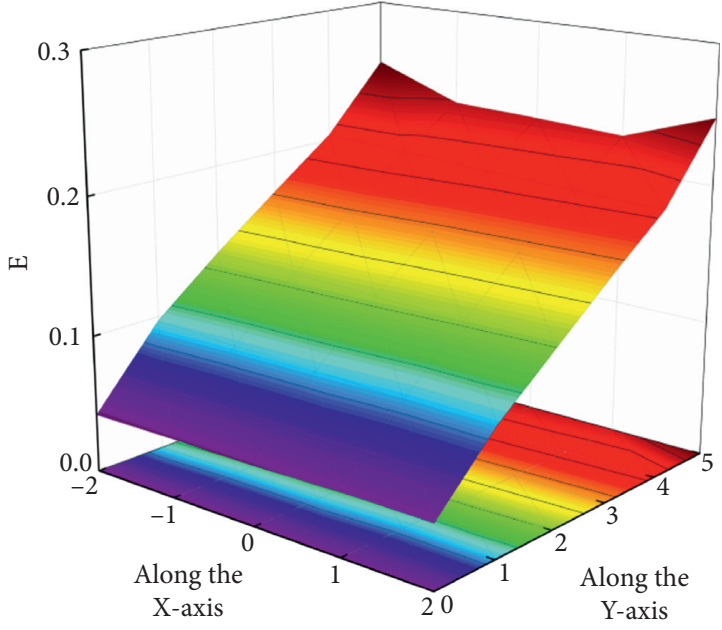

(b)

FIGURE 7: Response coefficient of hinge joint of rear connecting rod. (a) Impact response coefficient of the rear connecting rod. (b) Excitation response coefficient of the rear connecting rod. 


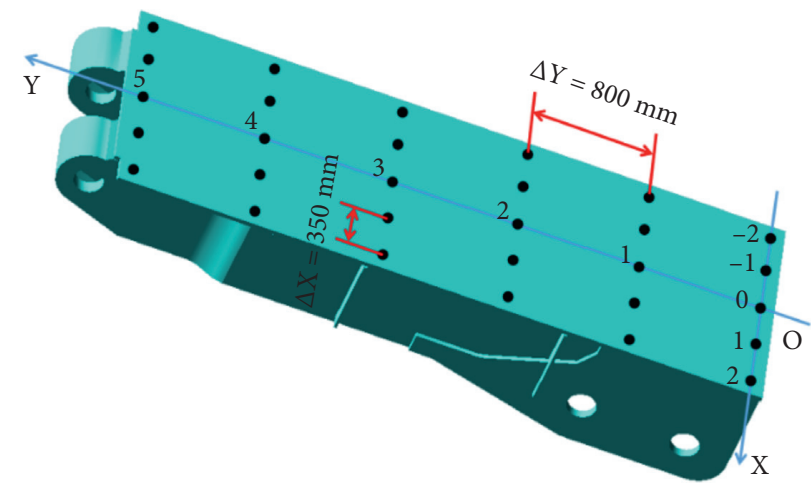

FIGURE 8: Loading position of shield beam of hydraulic support.

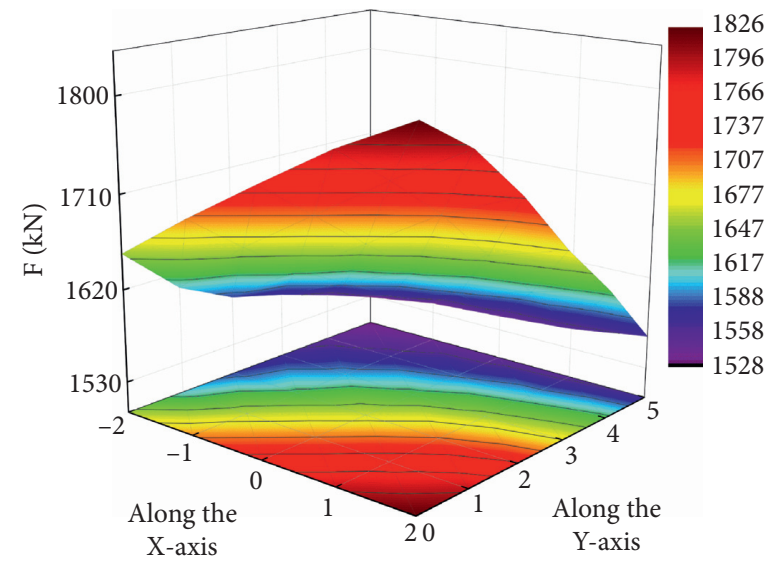

(a)

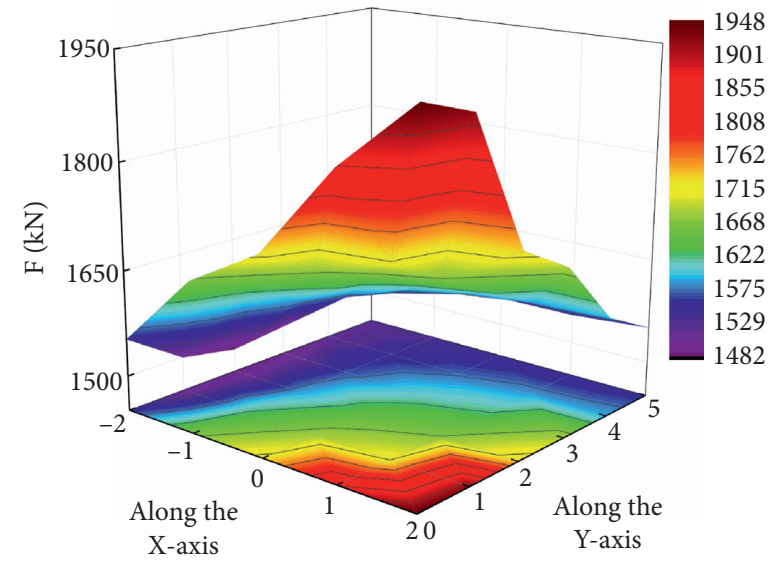

(b)

FIGURE 9: Response force of one side front column of hydraulic support. (a) Steady state response force of unilateral front column. (b) Peak response force of unilateral front column.

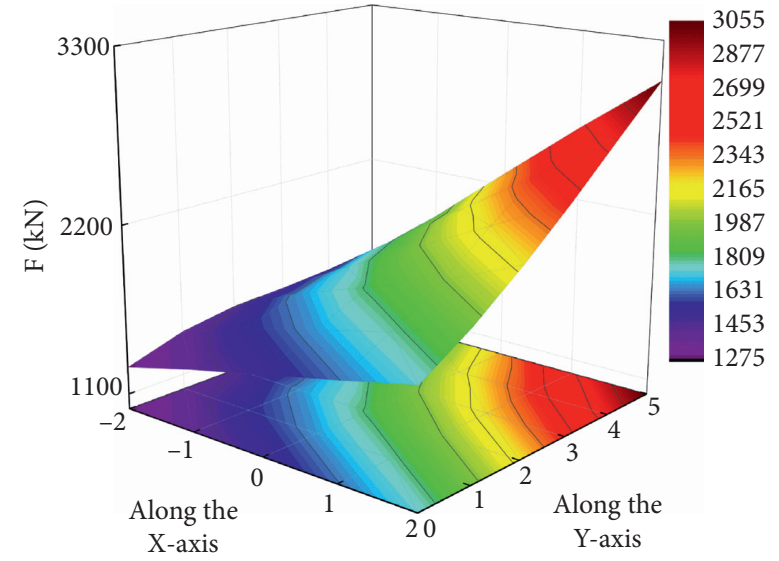

(a)



(b)

FIGURE 10: Response force of one side rear column of hydraulic support. (a) Steady state response force of unilateral rear column. (b) Peak response force of unilateral rear column.

relatively poor when the impact load is applied at this position. The peak response force of the rear column presents obvious impact fluctuation effect at the rear position of the shield beam; that is, compared with the front end of the shield beam, the rear column needs to have better impact adaptability when the impact load is applied at the back end of the shield beam.

The adaptability of the hinge pin of other structural parts of the hydraulic support to the impact load of the shield beam is also evaluated by the impact coefficient $I$ and the 
excitation coefficient $E$ in the upper section. The response coefficient at the hinge of the top beam-shield beam is shown in Figure 11.

By observing the variation law of impact response coefficient in Figure 11(a), it can be concluded that the overall variation trend augments with the increase of impact load position along the positive direction of $X$ - and $Y$-axes. Combined with the analysis of excitation response coefficient in Figure 11(b), it can be concluded that when the impact load acts on the shield beam, the hinged joints of the top beam and the shield beam have relatively good impact adaptability.

The response of the hinge of the four-link mechanism of the shield beam under impact load is shown in Figures 12 and 13. Based on the comparative analysis of the impact response coefficient in the two figures, it reinforces that along the width direction of the shield beam ( $X$-axis direction), the change of the impact load position has minor influence on the impact response coefficient, indicating that the front and rear connecting rods have certain resistance to partial load. The front and rear connecting rods change from the tension state to the compression state under the action of only static load; thus, when the impact load is large enough, the front and rear connecting rods will show the compression state. From the perspective of impact response coefficient, when the front of the shield beam is subjected to impact load, the force change is small with a relatively good adaptability to impact load.

When the position of the impact load changes along the width of the shield beam, the overall effect on the excitation response coefficient is not significant. Only when the impact load acts behind the shield beam at the hinge of the front and rear connecting rod (the side on which the $Y$-axis coordinates tend to 0 ) does the excitation coefficient fluctuate to a certain extent. When the position of impact load is close to the rear of shield beam, the hinge point of front and rear connecting rods is more sensitive to impact, and the response force of impact peak fluctuates greatly. After analyzing the impact response coefficient and excitation response coefficient of the hinge of front and rear connecting rods, it can be concluded that under the premise of impact load acting on the shield beam, when the impact position is close to the rear of the shield beam, the impact adaptability is poor compared to that of the impact position close to the front of the shield beam. In the design and optimization process of the support, the use requirements under this situation should be ensured.

\section{Adaptability Analysis of Hydraulic Support under Different Impact Loads}

In order to explore the adaptive change law of the impact dynamic load of the support under various impact conditions, the numerical simulation model mentioned above is adopted to conduct a detailed comparative analysis by taking different impact loads acting on the top beam of the hydraulic support as an example. The impact position of the middle line position in the width direction of the top beam is defined by taking points at equal spacing, as is shown in Figure 14 .

The coordinate system is established with the upper surface of the top beam as the reference plane. $X$ coordinate axis represents the width direction of the top beam, Y coordinate axis represents the length direction of the top beam, and the origin of the coordinate system $\mathrm{O}$ is at the center of the width direction of the top beam. On the $\mathrm{Y}$ coordinate axis, the points are taken at an equal interval of $914 \mathrm{~mm}$, and the points are numbered.

\subsection{Adaptability Analysis of Support under Different Impact} Strengths. In order to explore the adaptive change law of the bracket under different impact strengths, the STEP function is used to apply impact loads to five positions on the upper surface of the top beam in combination with the above simulation model. Among them, the size of the control load is a single variable, and the impact velocity and other factors remain unchanged. The impact loads are $1500 \mathrm{kN}, 2000 \mathrm{kN}$, and $2500 \mathrm{kN}$, respectively, and the impact time is $0.05 \mathrm{~s}$. The change rule of the front and back columns with the hydraulic support under different impact loads is shown in Figures 15 and 16.

According to the analysis results, the impact response force of the front and rear columns endures impacts of the impact load, and the increase of the impact load will make the tension or compression of the column suffer more serious consequences, or even cause the failure of the column. The difference is that when the impact load acts on the front end of the top beam, the front column is more sensitive to the change of the impact load, and when the impact load acts on the front and rear ends of the top beam, the back column is relatively sensitive to the change of the impact load.

The response law of each hinge is simulated and analyzed by using the same impact load with specific results shown in Tables 2-4. The results show that the impact response coefficient basically does not change with the change of the size of the load; that is, the impact response force of the pin at the hinge is proportional to the size of the impact load, and the force at the component hinge will increase proportionately with the increase of the impact load.

The response results of excitation coefficient at the hinge of each component with the increase of impact load are shown in Figure 17. From the perspective of excitation response coefficient, the response coefficients of the hinge between the top beam and the shield beam, the front connecting rod and the shield beam, and the rear connecting rod and the shield beam are all affected by the impact load and become larger with the augment of the impact load, which makes the force fluctuation of each hinge become larger, reducing the adaptability of the hydraulic support to the impact dynamic load.

\subsection{Adaptability Analysis of Support under Different Impact} Velocities. By changing the loading time in STEP function, the adaptability of hydraulic support to impact dynamic load under different impact velocities is simulated. The impact time is set as $0.05 \mathrm{~s}, 0.03 \mathrm{~s}$, and $0.01 \mathrm{~s}$, respectively, the impact 




(a)

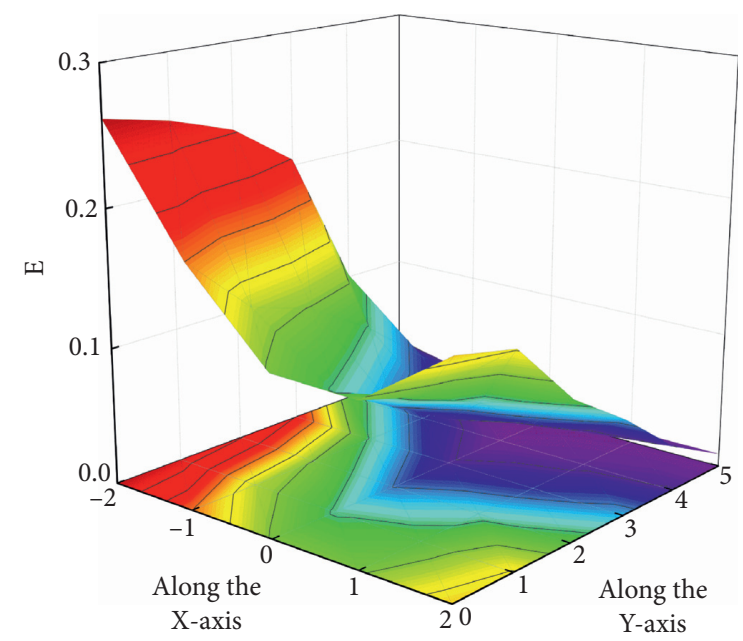

(b)

FIGURE 11: Response coefficient of hinge joint between canopy and goaf shield. (a) Impact response coefficient of top beam and shield beam. (b) Excitation response coefficient of top beam and shield beam.

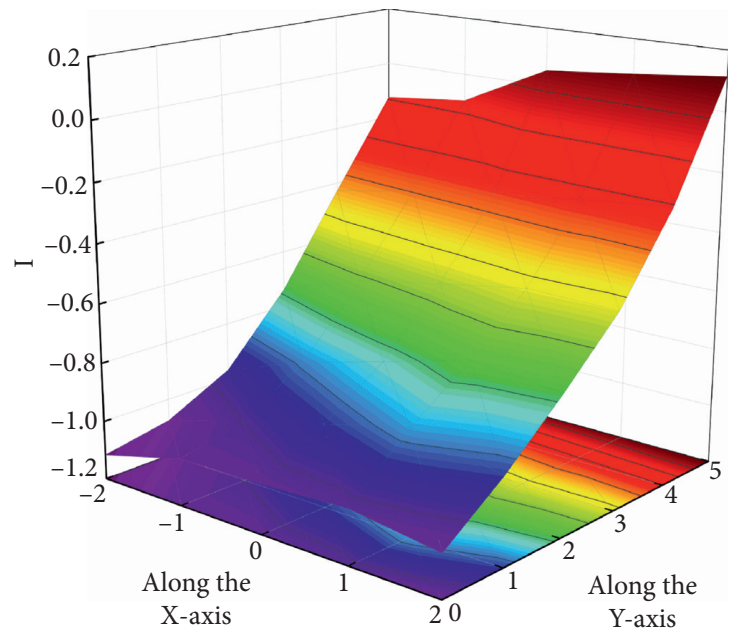

(a)

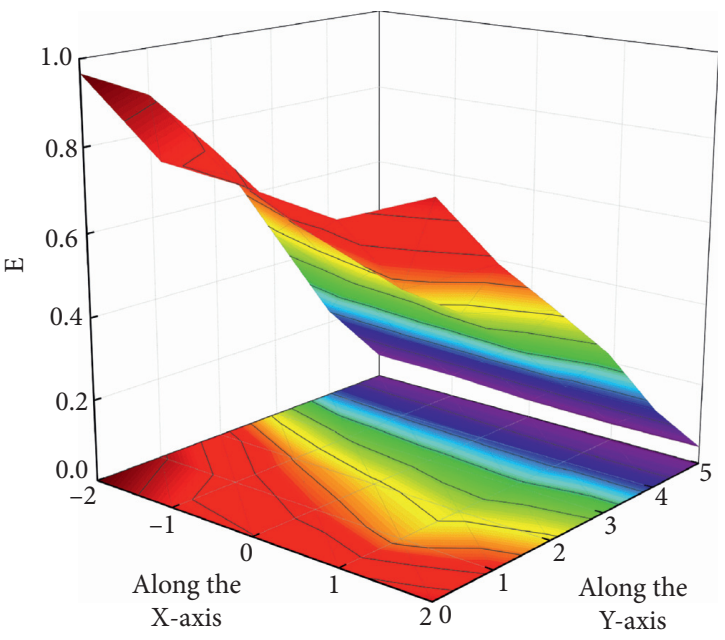

(b)

FIGURE 12: Response coefficient of hinge joint of front connecting rod. (a) Impact response coefficient of the front connecting rod. (b) Excitation response coefficient of the front connecting rod.

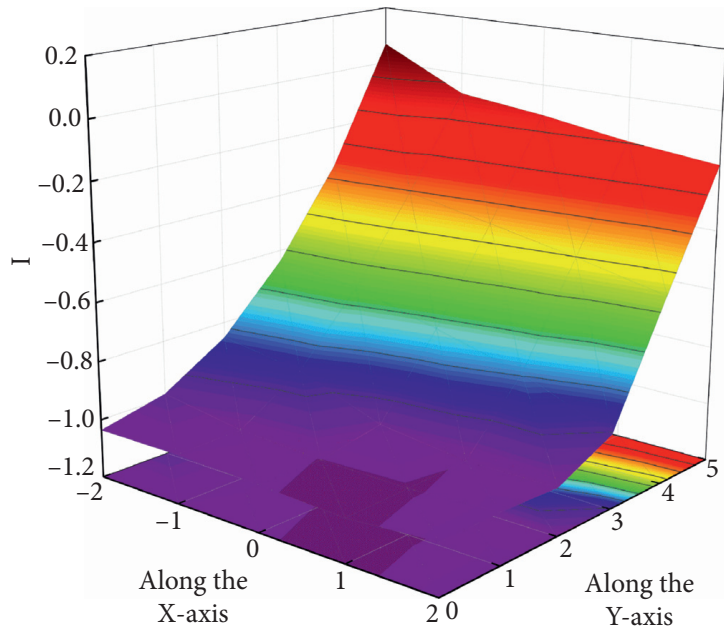

(a)

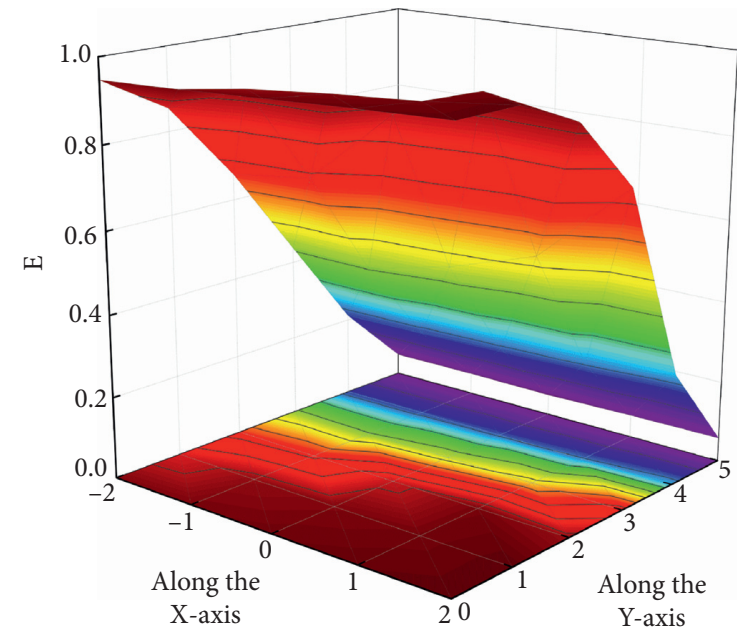

(b)

FIGURE 13: Response coefficient of hinge joint of rear connecting rod. (a) Impact response coefficient of rear connecting rod. (b) Excitation response coefficient of the rear connecting rod. 


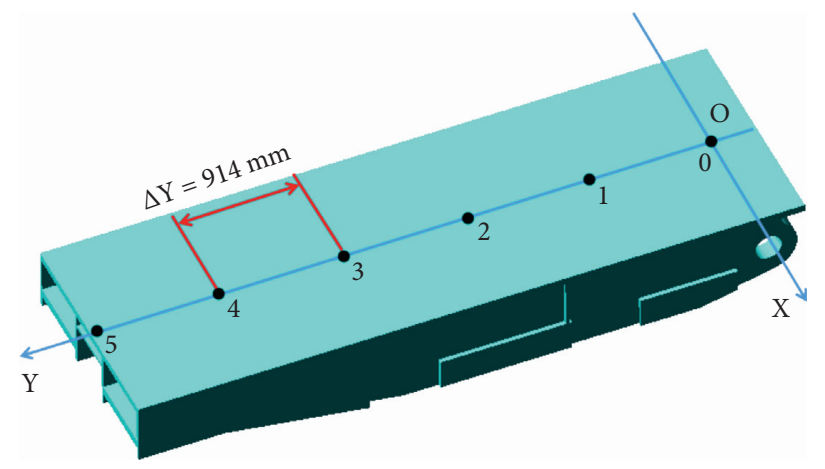

FIgURE 14: Position of impact load on canopy.

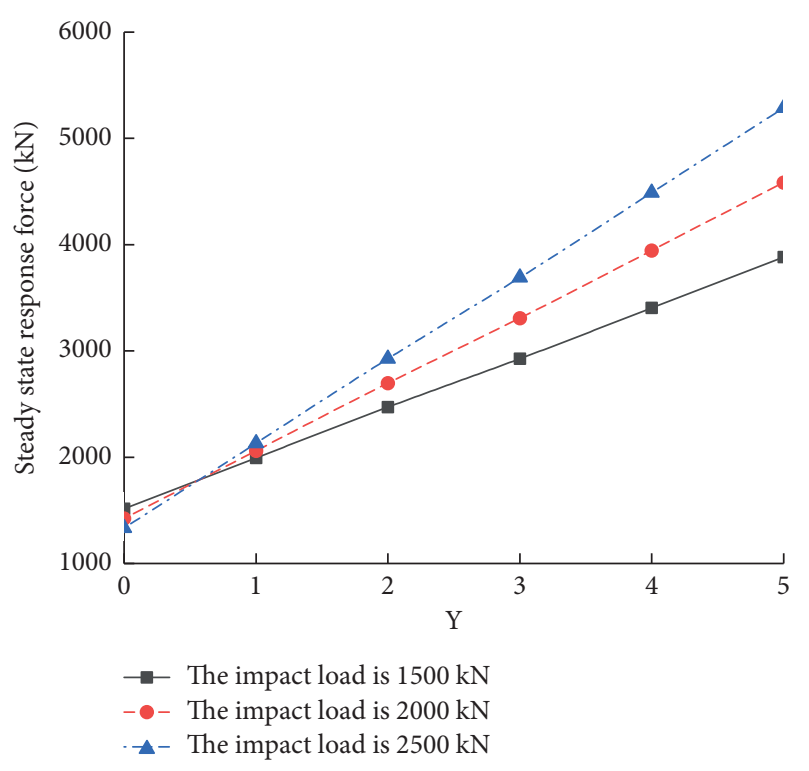

(a)

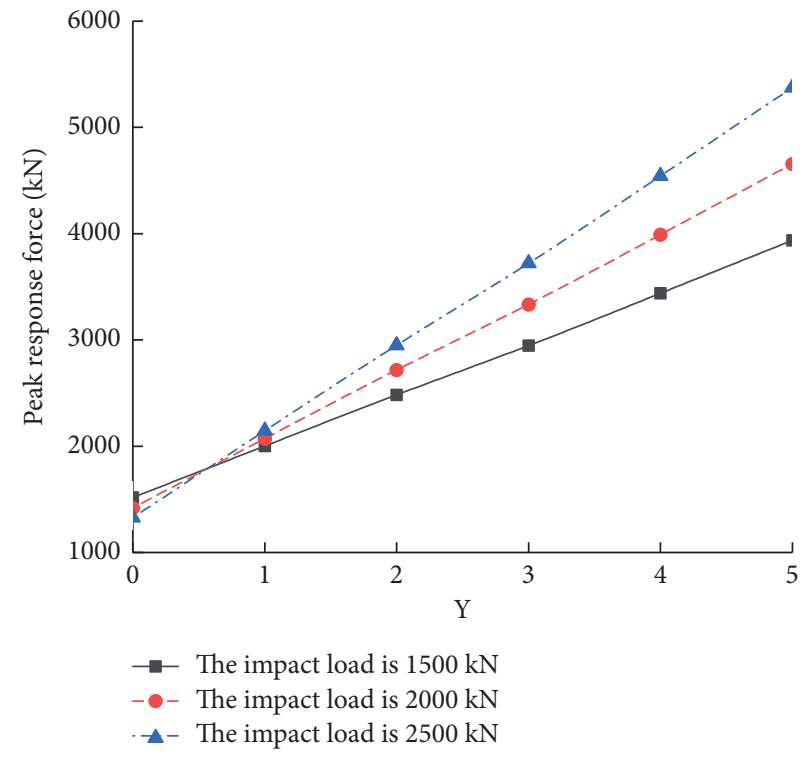

(b)

FIGURE 15: Response force of one side front column of hydraulic support. (a) Steady state response force of unilateral front column. (b) Peak response force of unilateral front column.

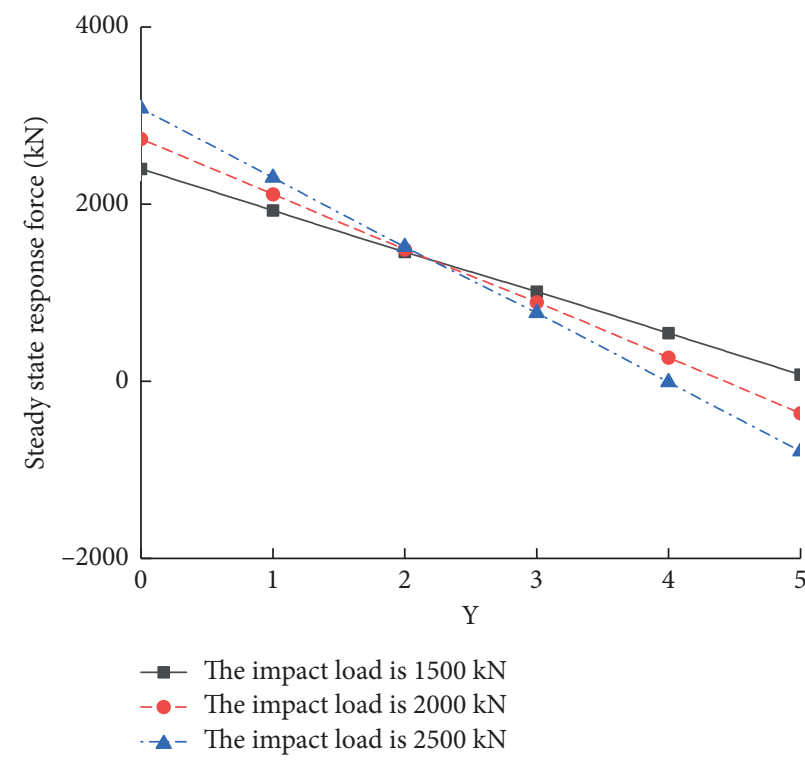

(a)

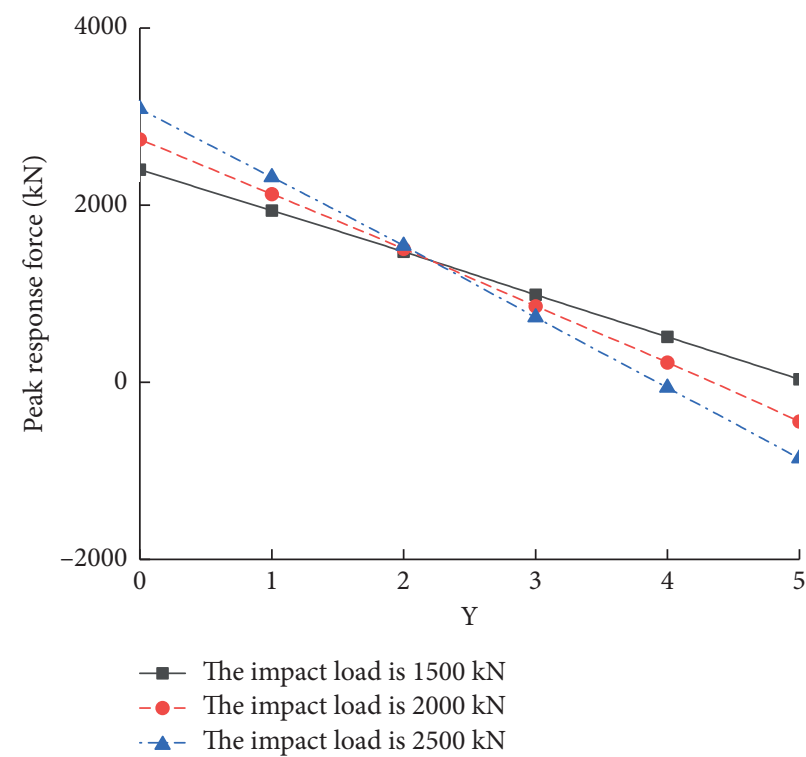

(b)

FiguRE 16: Response force of one side rear column of hydraulic support. (a) Steady state response force of unilateral rear column. (b) Peak response force of one side rear column. 
TABLE 2: Impact response coefficient at the joint of canopy and goaf shield.

\begin{tabular}{lccccrr}
\hline Position & $(0,0)$ & $(0,1)$ & $(0,2)$ & $(0,3)$ & $(0,4)$ & $(0,5)$ \\
\hline Load size $1500 \mathrm{kN}$ & 0.094 & 0.070 & 0.097 & 0.130 & 0.166 & 0.202 \\
Load size 2000 kN & 0.095 & 0.070 & 0.097 & 0.131 & 0.167 & 0.203 \\
Load size 2500 kN & 0.96 & 0.070 & 0.098 & 0.131 & 0.167 & 0.203 \\
\hline
\end{tabular}

TABLE 3: Impact response coefficient of hinge joint of front connecting rod.

\begin{tabular}{llllllr}
\hline Position & $(0,0)$ & $(0,1)$ & $(0,2)$ & $(0,3)$ & $(0,4)$ & $(0,5)$ \\
\hline Load size $1500 \mathrm{kN}$ & 0.161 & 0.360 & 0.553 & 0.743 & 0.946 & 1.150 \\
Load size 2000 kN & 0.161 & 0.360 & 0.554 & 0.744 & 0.947 & 1.151 \\
Load size 2500 kN & 0.162 & 0.361 & 0.554 & 0.744 & 0.947 \\
\hline
\end{tabular}

TABLE 4: Impact response coefficient of hinge joint of rear connecting rod.

\begin{tabular}{lllllll}
\hline Position & $(0,0)$ & $(0,1)$ & $(0,2)$ & $(0,3)$ & $(0,4)$ & $(0,5)$ \\
\hline Load size $1500 \mathrm{kN}$ & 0.150 & 0.334 & 0.513 & 0.689 & 0.876 \\
Load size $2000 \mathrm{kN}$ & 0.150 & 0.334 & 0.513 & 0.689 & 0.877 & 1.066 \\
Load size 2500 kN & 0.150 & 0.334 & 0.513 & 0.690 & 0.878 \\
\hline
\end{tabular}

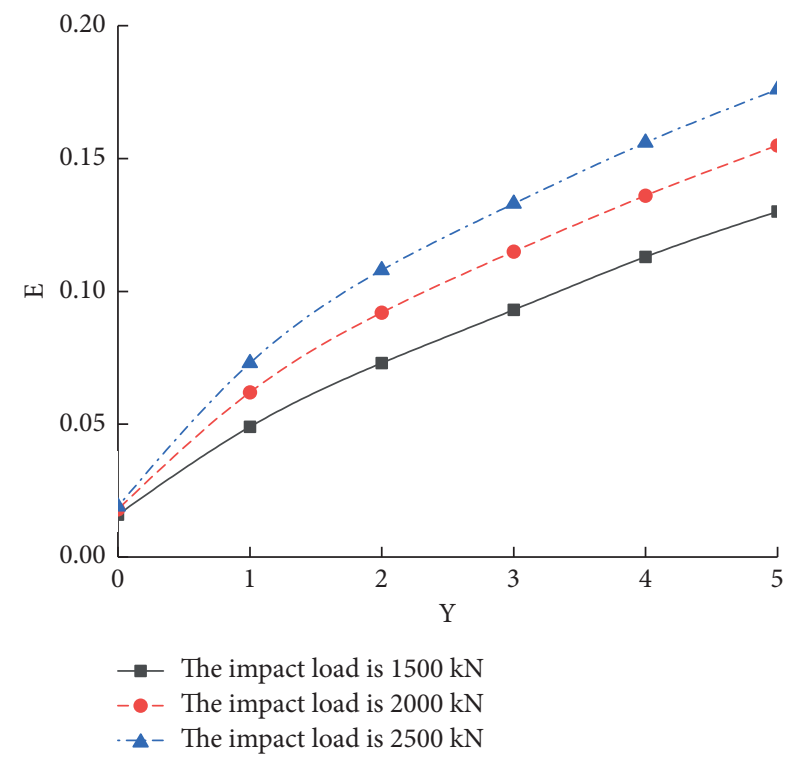

(a)

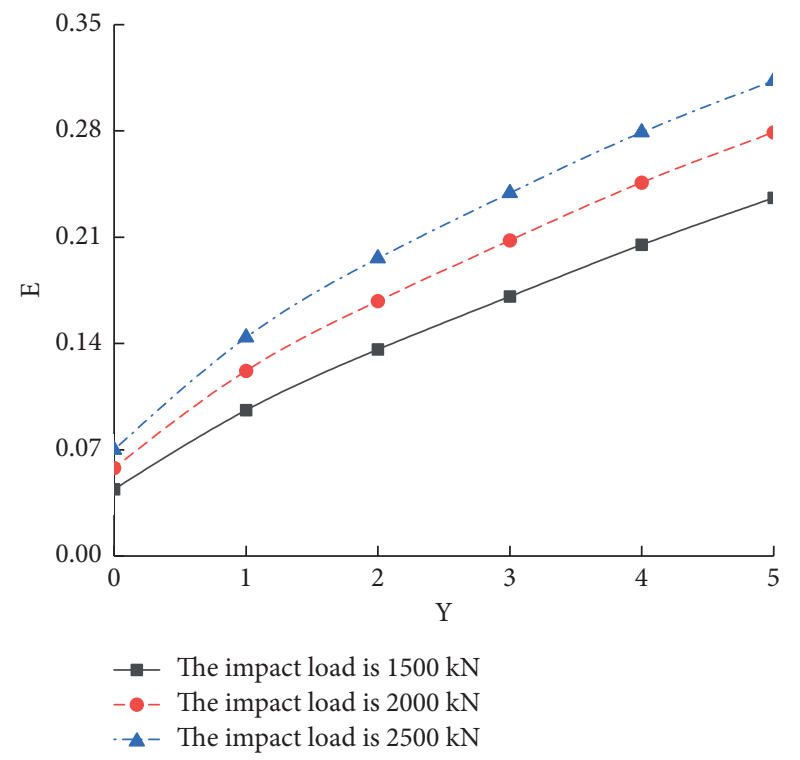

(b)

Figure 17: Continued. 


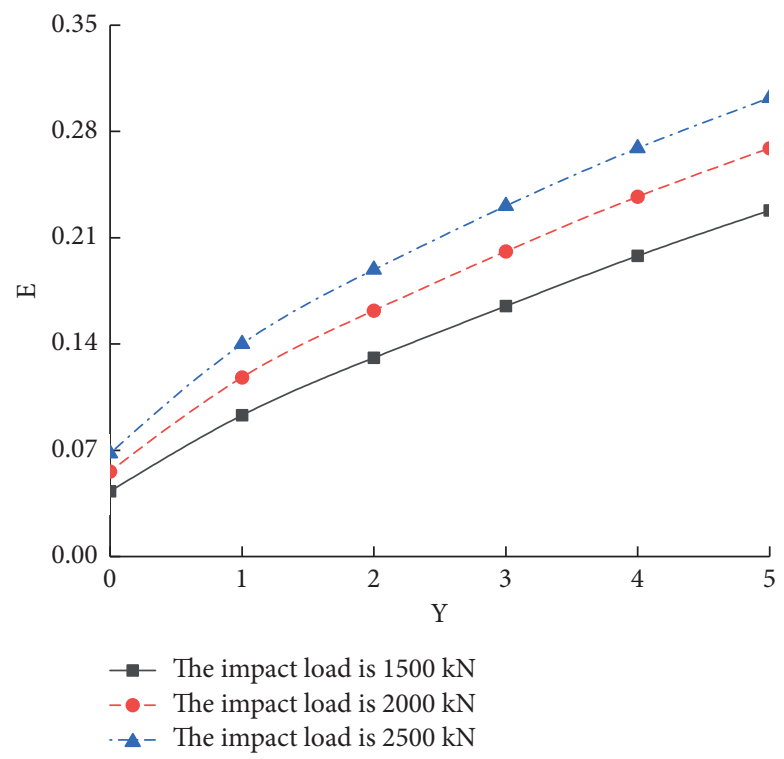

(c)

FigURE 17: Excitation response coefficient of each hinge point. (a) Excitation response coefficient of top beam and shield beam. (b) Excitation response coefficient of the front connecting rod. (c) Excitation response coefficient of the rear connecting rod.

TABLE 5: Steady state response force of front column.

\begin{tabular}{lcccccc}
\hline Position & $(0,0)(\mathrm{kN})$ & $(0,1)(\mathrm{kN})$ & $(0,2)(\mathrm{kN})$ & $(0,3)(\mathrm{kN})$ & $(0,4)(\mathrm{kN})$ & $(0,5)(\mathrm{kN})$ \\
\hline Impact time 0.05 s & 1514.2 & 1992.2 & 2470.1 & 2927.5 & 3405.8 & 3884.4 \\
Impact time 0.03 s & 1514.2 & 1992.2 & 2470.2 & 2927.5 & 3405.8 & 3884.3 \\
Impact time 0.01 s & 1514.1 & 1992.1 & 2470.1 & 2927.4 & 3405.7 \\
\hline
\end{tabular}

TABLE 6: Steady state response force of rear column.

\begin{tabular}{lcccccc}
\hline Position & $(0,0)(\mathrm{kN})$ & $(0,1)(\mathrm{kN})$ & $(0,2)(\mathrm{kN})$ & $(0,3)(\mathrm{kN})$ & $(0,4)(\mathrm{kN})$ & $(0,5)(\mathrm{kN})$ \\
\hline Impact time 0.05 s & 2396.7 & 1928.5 & 1460.2 & 1012.1 & 543.33 & 74.38 \\
Impact time 0.03 s & 2396.6 & 1928.5 & 1460.3 & 1012.1 & 543.34 & 74.38 \\
Impact time 0.01 s & 2396.7 & 1928.4 & 1460.3 & 1012.1 & 543.33 \\
\hline
\end{tabular}

load is set as $1500 \mathrm{kN}$, and other control conditions remain unchanged. The variation rule of steady-state response forces of front and rear columns is shown in Tables 5 and 6 .

By analyzing the data in Tables 5 and 6, the steady-state impact response forces of the front and rear columns are not affected by the impact load velocity, and the steady-state force values at the hinge points of other components are not changed with the impact load velocity. It can be implied that the top pressure velocity will not affect the final steady-state force of the hydraulic support. From the perspective of the steady-state response, it will not exert an impact on the impact adaptability of the support.

The variation rule of the impact peak response force of the front and rear columns is illustrated in Figure 18. Combined with the peak response force analysis of the front and rear columns, the impact velocity has faint effect on the column in general. When the impact load point is positioned close to the front end of the top beam, the acceleration of the impact velocity will make the force fluctuation of the column larger before columns reach to the steady-state force, thus resulting in the decrease of the impact adaptability of the support.

The variation rule of impact response at the hinge of top beam and shield beam is shown in Figure 19. As can be seen from the figure, the acceleration of impact speed will lead to the increase in the stress at the hinge point of the top beam and the shield beam, and the peak value of impact response force, which will call for higher requirements for the use of the articulated pin shaft here. In addition, the front-end position of the top beam is sensitive to the velocity change of the impact load. When the impact load acts on this point, the increase of the impact velocity will greatly reduce the adaptability of the impact dynamic load at the hinge point.

The response coefficient of the front and rear connecting rods at the hinge point of the shield beam varies with the impact velocity with its change rule shown in Figures 20 and 21. Combined with the comparative analysis of impact response coefficient and excitation response coefficient, it can 


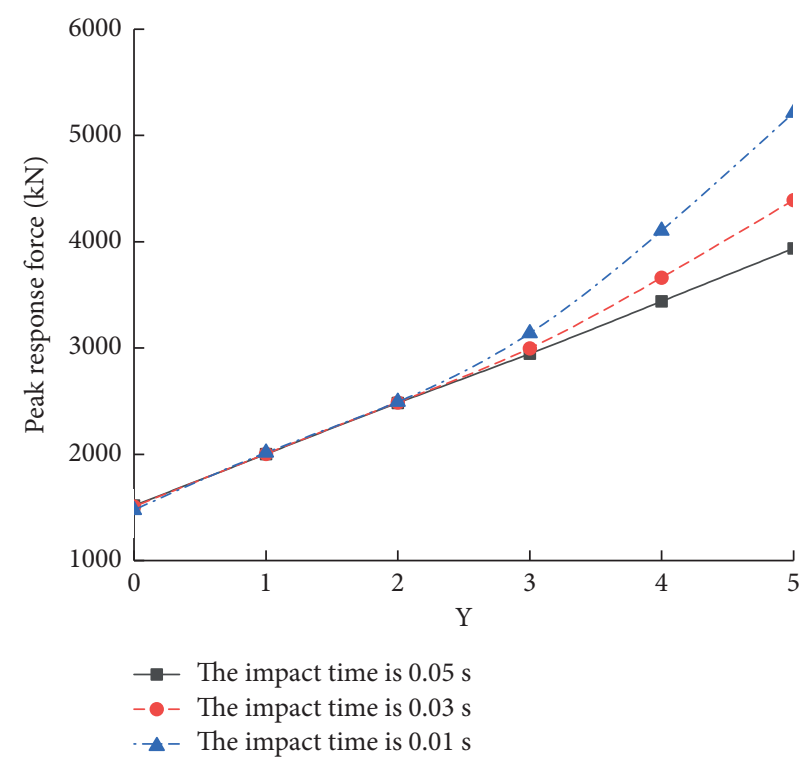

(a)

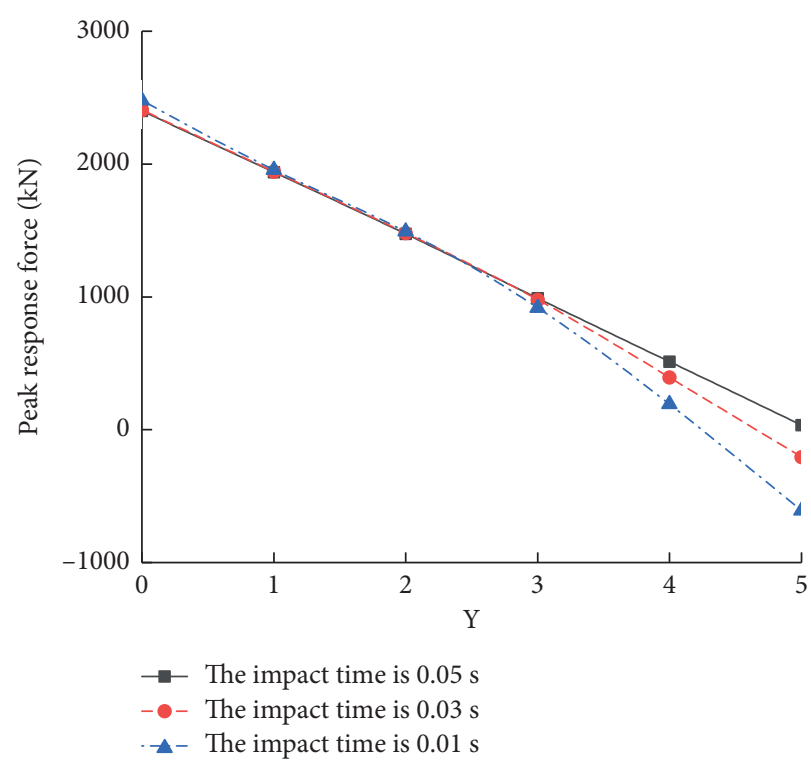

(b)

Figure 18: Peak response force of one side column of hydraulic support. (a) Peak response force of unilateral front column. (b) Peak response force of unilateral rear column.

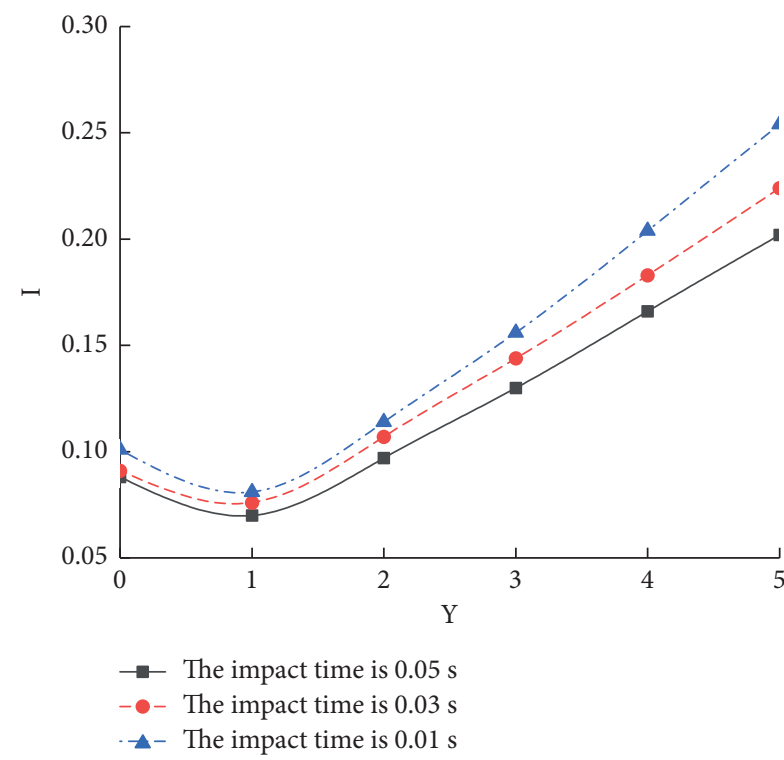

(a)

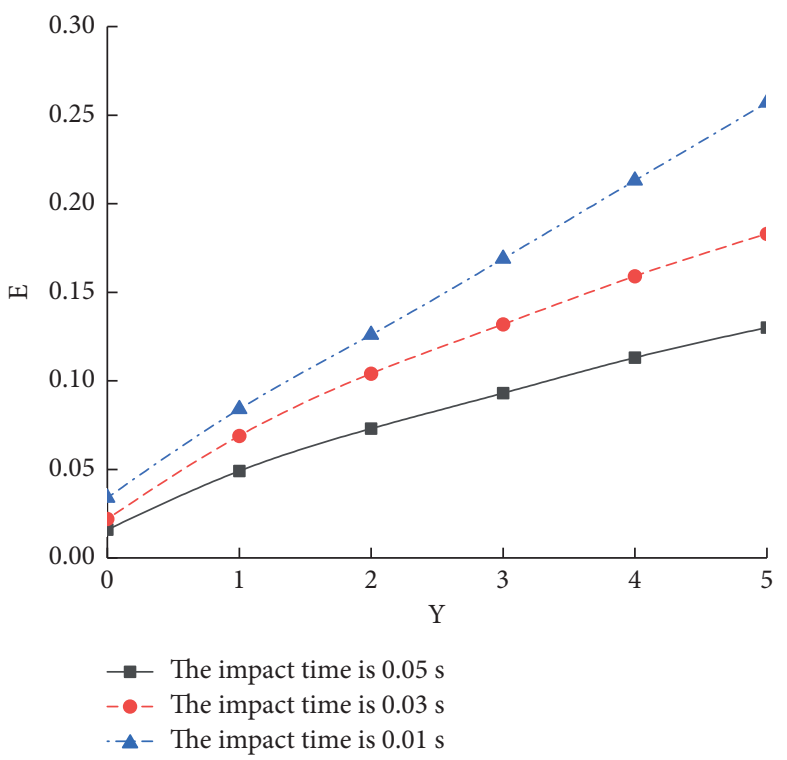

(b)

Figure 19: Response coefficient of hinge joint between canopy and goaf shield. (a) Impact response coefficient of top beam and shield beam. (b) Excitation response coefficient of top beam and shied beam.

be concluded that the stress at the hinge point of the front and rear connecting rods will extend due to the increase of the impact load velocity caused by the roof compression, and the stress fluctuation at the hinge point will become larger, resulting in the bad stress at the hinge point. When the impact load acts on the front end of the top beam, the impact velocity has a great influence on the dynamic load adaptability of the front and rear connections and rod hinged joints. The acceleration of the impact velocity will greatly weaken the dynamic load adaptability of the top beam. 


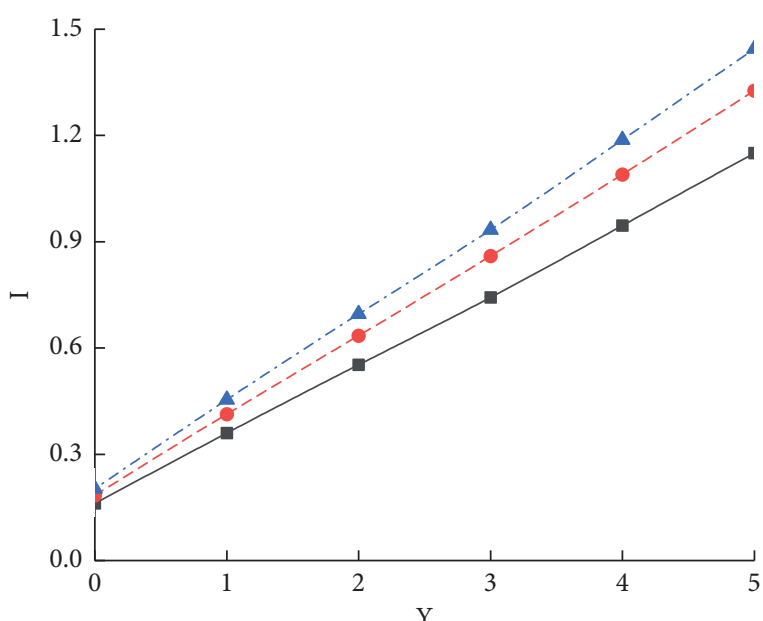

$\rightarrow$ - The impact time is $0.05 \mathrm{~s}$

- The impact time is $0.03 \mathrm{~s}$

- The impact time is $0.01 \mathrm{~s}$

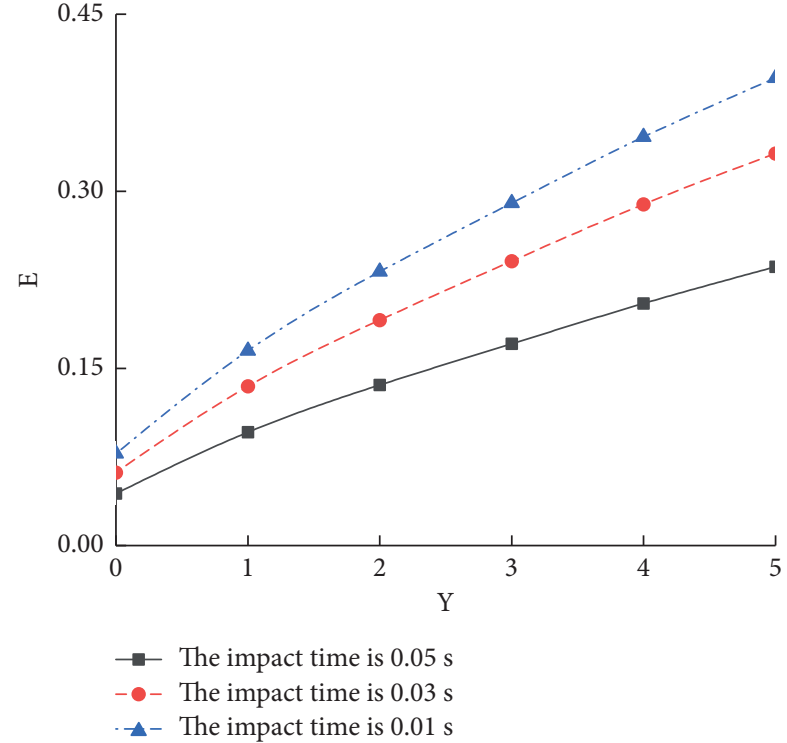

(b)

FIGURE 20: Response coefficient of hinge joint of front connecting rod. (a) Impact response coefficient of the front connecting rod. (b) Excitation response coefficient of the front connecting rod.

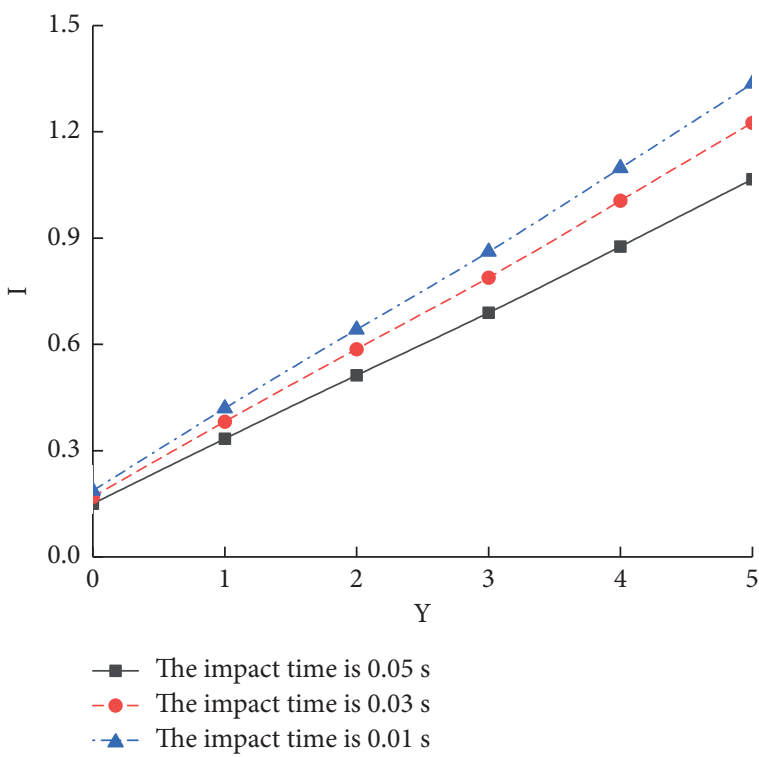

(a)



(b)

FIGURE 21: Response coefficient of hinge joint of rear connecting rod. (a) Impact response coefficient of rear connecting rod. (b) Excitation response coefficient of the rear connecting rod. 


\section{Conclusions}

(1) When the same impact load acts on different positions of the top beam of the support, the closer the impact load is to a column, the greater the change of the steady-state response force of the column will be. The impact load changes the steady-state response force of the column; however, compared with and the hinged part of other components, the difference between the peak response force and the steady-state response force is always small with the slight force fluctuation. The impact adaptability of each hinge of other components is poor when the impact load acts on the front end of the top beam, with a due full consideration given to the process of designing and optimizing the hydraulic support.

(2) When the same impact load acts behind the shield beam, the steady-state response force of the front column is greatly affected. Additionally, when the impact load acts on the front of the shield beam, the steady-state response force of the rear column is greatly affected. Moreover, the difference between the peak response force and the steady-state response force of the front and rear columns is still slight. Other hinged joints have the same response characteristics; that is, when the impact load is positioned in front of the shield beam, the impact response is obvious; and when the impact load acts behind the shield beam, the excitation response is evident. Therefore, in the process of using the hydraulic support, its impact adaptability characteristics should be considered comprehensively to ensure that the pins meet the requirements of use.

(3) Taking the impact load acting on the top beam as an example, it can be concluded that the increase of the compressive strength and speed of the roof generally has a great impact on the impact adaptability of the hydraulic support column and the pin shaft at each hinged part, which will reduce the impact dynamic load adaptability, more easily leading to the column damage under tension and compression and the pin shaft wear and fracture failure. Therefore, in the process of working face mining, changing the roof stress conditions by means of high-pressure water injection should be taken into consideration for controlling the gradual and slow release of roof stress.

\section{Abbreviations}

A: $\quad$ Effective pressure area in the hydraulic cylinder

$C_{c}$ : Damping coefficient of the contact member

$e: \quad$ Stiffness to force contribution gain

$E_{(X, Y)}$ : Excitation response coefficient at the component hinge when the impact load is applied to the position $(\mathrm{X}, \mathrm{Y})$ of the top beam

$F_{c}$ : $\quad$ Contact force between roof and top beam

$F_{I}$ : $\quad$ Size of the applied impact load

$F_{\text {max }}$ : Peak response force of the corresponding hinge point under external impact load
$F_{o}$ : Size of the steady-state response force at the hinge point under static load when the hydraulic support is only subjected to static load

$F_{s}: \quad$ Steady-state response forces at the hinge points after the impact load is applied to the top beam

$I_{(X, Y)}$ : Impact response coefficient of the pin at the hinge when the impact load is applied to the position $(\mathrm{X}, \mathrm{Y})$ of the top beam

$k$ : $\quad$ Stiffness coefficient of the equivalent spring

$k$ : Stiffness coefficient of two-stage hydraulic cylinder series equivalent spring

$k_{1}$ : $\quad$ Equivalent stiffness coefficient of primary cylinder

$k_{2}$ : $\quad$ Equivalent stiffness coefficient of secondary cylinder

$K_{H}$ : $\quad$ Plane contact impact stiffness

$L_{y}$ : $\quad$ Length of effective liquid column in hydraulic cylinder

$V_{c}$ : Normal relative velocity of the contact member

$\delta_{c}: \quad$ Normal penetration depth of contact member

$\eta$ : $\quad$ Bulk modulus of elasticity of hydraulic fluids.

\section{Data Availability}

The results of simulations and experiments are shown in the figures and data used to support the findings of this study are included within the article.

\section{Conflicts of Interest}

The authors declare that there are no conflicts of interest regarding the publication of this paper.

\section{Acknowledgments}

This work was supported by the Coal Science and Industry Group Science and Technology Innovation Fund Project of China (grant numbers 2018-TD-ZD015 and 2020-TDZD015).

\section{References}

[1] W. Guofa, "Research on mining technology with high mining height and development of powered support for high mining height," Coal miningTechnology, vol. 14, no. 1, pp. 1-4, 2009.

[2] M. E. Yetkin, F. Simsir, M. K. Ozfirat, P. M. Ozfirat, and H. Yenice, "A fuzzy approach to selecting roof supports in longwall mining," South African Journal of Industrial Engineering, vol. 27, no. 1, pp. 162-177, 2016.

[3] M. K. Özfirat, "A fuzzy method for selecting underground coal mining method considering mechanization criteria," Journal of Mining Science, vol. 48, no. 3, pp. 533-544, 2012.

[4] S. Prusek, M. Płonka, and A. Walentek, "Applying the ground reaction curve concept to the assessment of shield support performance in longwall faces," Arabian Journal of Geosciences, vol. 9, no. 3, p. 167, 2016.

[5] T. M. Barczak, G. S. Esterhuizen, J. L. Ellenberger, and P. Zhang, "A first step in developing standing roof support design criteria based on ground reaction data for pittsburgh seam longwall tailgate support," in Proceedings of the 27th International conference on ground control in mining, pp. 347-357, West Virginia, USA, July 2008. 
[6] B. Brady and E. Brown, Rock Mechanics for Underground mining, Springer, Berlin, Germany, Third edition, 2006.

[7] T. P. Medhurst, "Practical considerations in longwall support behavior and ground response," Journal of the American Society for Mass Spectrometry, vol. 16, no. 10, pp. 1583-1594, 2005.

[8] D. Szurgacz and J. Brodny, "Adapting the powered roof support to diverse mining and geological conditions," Energies, vol. 13, no. 3, p. 405, 2020.

[9] M. Witek and S. Prusek, "Numerical calculations of shield support stress based on laboratory test results," Computers and Geotechnics, vol. 72, pp. 74-88, 2016.

[10] W. Guofa, L. Junfeng, and R. Huaiwei, "Design and optimization of high seam-caving coal hydraulic support based on model of support and wall rock coupling," Journal of China Coal Society, vol. 36, no. 01, pp. 145-151, 2011.

[11] W. Guofa and P. Yihui, "Shield-roof adaptability evaluation method based on coupling of parameters between shield and roof strata," Journal of China Coal Society, vol. 41, no. 6, pp. 1348-1353, 2016.

[12] W. Guofa, P. Yihui, and Li Mingzhong, "Hydraulic support and coal wall coupling relationship in ultra large height mining face," Journal of China Coal Society, vol. 42, no. 02, pp. 518-526, 2017.

[13] W. Guo and P. Yihui, "Full-mechanized coal mining and caving mining method evaluation and key technology for thick coal seam," Journal of China Coal Society, vol. 43, no. 01, pp. 33-42, 2018.

[14] W. Guofa, Li Xiyong, and Z. Chuanchang, "Research and development and application of set equipment of $8 \mathrm{~m}$ large mining height fully-mechanized face," Coal Science and Technology, vol. 45, no. 11, pp. 1-8, 2017.

[15] R. Huaiwei, Du. Yibo, and H. Gang, "Self adaptive support control method of hydraulic support-surrounding rock in fully-mechanized coal mining face," Coal Science and Technology, vol. 46, no. 01, pp. 150-155, 2018.

[16] W. Guofa, Hu Xiangpeng, and L. Xinhua, "Adaptability analysis of four-leg hydraulic support for underhand working face with large mining height of kilometer deep mine," Journal of China Coal Society, vol. 45, no. 03, pp. 865-875, 2020.

[17] He Shangsen, Overburden Strata Behavior of Close Distance Coal Seams and its Control, China University of Mining and Technology-Beijing, Beijing, China, 2017.

[18] M. Zhaosheng, Z. Qingliang, and W. Lirong, "Support performance and canopy adaptability of shield support," Journal of China Coal Society, vol. 43, no. 04, pp. 1162-1170, 2018.

[19] Li Mingzhong, Research on Key Technology of Fully Mechanized Top Coal Caving Method with Great Mining Height in Hard and Extra Thick Coal Seam in Yushen Mining Area, China Coal Research Institute, China, 2018.

[20] Z. Meng, Q. Zeng, K. Gao, S. Kong, P. Liu, and L. Wan, "Failure analysis of super-large mining height powered support," Engineering Failure Analysis, vol. 92, pp. 378-391, 2018.

[21] Q. L. Zeng, Z. S. Meng, L. R. Wan, and C. L. Wang, "Analysis on force transmission characteristics of two-legged shield support under impact loading," Shock and Vibration, vol. 2018, Article ID 3854684, 10 pages, 2018. 